\title{
Les emplois représentent plus que des revenus
}

Dernière mise à jour : 14 mars 2016

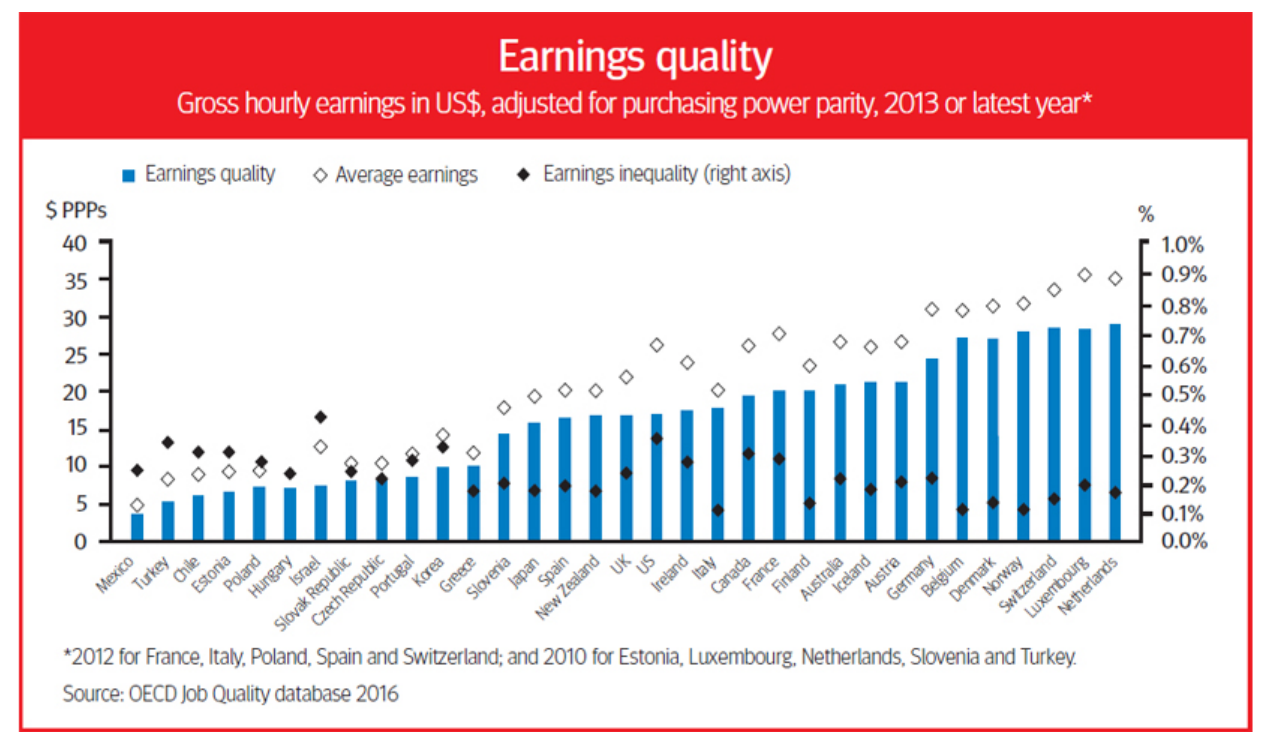

En ce qui concerne l'emploi et les revenus, la qualité compte aussi. En effet, comme il a déjà été écrit dans ces pages, un bon salaire, la sécurité de l'emploi et des conditions de travail décentes vont de pair avec un taux d'emploi élevé. De nouvelles données de l'OCDE sur la qualité de l'emploi dans 45 pays étayent cet avis. Les données portent sur trois grandes dimensions du bien-être : la qualité des revenus d'activité, c'est-à-dire la contribution de l'emploi au niveau de vie matériel et à la distribution des revenus dans la population active ; la sécurité de l'emploi, à savoir le risque de chômage et son coût ; et la qualité de l'environnement de travail.

Selon l'analyse des données, l'Allemagne, l'Australie, l'Autriche, le Danemark, la Finlande, le Luxembourg, la Norvège et la Suisse présentent la meilleure qualité globale de l'emploi (avec de bons résultats pour au moins deux dimensions) et l'Espagne, l'Estonie, la Grèce, la Hongrie, l'Italie, la Pologne, le Portugal, la République slovaque et la Turquie, la plus médiocre. S'agissant de la qualité des revenus (voir graphique), les Pays-Bas, le Luxembourg et la Suisse sont en tête, tandis que le Mexique, la Turquie et le Chili sont à la traîne, l'Italie, le Japon ou les États-Unis tenant le milieu du classement. Il apparaît également que les travailleurs jeunes ou peu qualifiés gagnent moins et subissent plus d'insécurité et de tensions que les autres. Les femmes ont des taux d'emploi et des salaires bien inférieurs à ceux des hommes, mais elles sont également soumises à moins de tension au travail. 
OL'Observateur de l'OCDE T1 2016

Plus de données et d'informations sur la qualité de l'emploi

See also Des emplois meilleurs et plus nombreux pour une reprise inclusive by Martine Durand and Stefano Scarpetta in OECD Yearbook 2015. 